\title{
Properties and Performance Verification on Magnetite Polydimethylsiloxane Graphene Array Microwave Sensor
}

\author{
Mohd Aminudin Jamlos ${ }^{1, *}$, Mohd Faizal Jamlos ${ }^{2, *}$, Azri Alias ${ }^{3}$, Mohamad Shaiful Abdul Karim ${ }^{2}$, \\ Wan Azani Mustafa ${ }^{1}$ (D) and Prayoot Akkaraekthalin ${ }^{4, *}$ \\ 1 Faculty of Electronic Engineering Technology, Universiti Malaysia Perlis, Kampus Alam UniMAP, Pauh Putra, \\ Arau 02600, Malaysia; wanazani@unimap.edu.my \\ 2 College of Engineering, Universiti Malaysia Pahang, Kuantan 26300, Malaysia; mshaiful@ump.edu.my \\ 3 Faculty of Mechanical and Automotive Engineering Technology, College of Engineering Technology, \\ Universiti Malaysia Pahang, Pekan 26600, Malaysia; azribalias@ump.edu.my \\ 4 Faculty of Engineering, King Mongkut's University of Technology North Bangkok, Bangkok 10800, Thailand \\ * Correspondence: mohdaminudin@unimap.edu.my (M.A.J.); mohdfaizaljamlos@gmail.com (M.F.J.); \\ prayoot.a@eng.kmutnb.ac.th (P.A.)
}

\section{check for} updates

Citation: Jamlos, M.A.; Jamlos, M.F.; Alias, A.; Karim, M.S.A.; Mustafa, W.A.; Akkaraekthalin, P. Properties and Performance Verification on Magnetite Polydimethylsiloxane Graphene Array Microwave Sensor. Polymers 2021, 13, 3254. https:// doi.org/10.3390/polym13193254

\section{Academic Editors:}

Michał Czerwiński, Karol Stasiewicz and Michał Dudek

Received: 10 August 2021

Accepted: 15 September 2021

Published: 24 September 2021

Publisher's Note: MDPI stays neutral with regard to jurisdictional claims in published maps and institutional affiliations.

Copyright: (c) 2021 by the authors. Licensee MDPI, Basel, Switzerland. This article is an open access article distributed under the terms and conditions of the Creative Commons Attribution (CC BY) license (https:// creativecommons.org/licenses/by/ $4.0 /)$.

\begin{abstract}
This paper investigates the use of a Magnetite Polydimethylsiloxane (PDMS) Graphene array sensor in ultra-wide band (UWB) spectrum for microwave imaging applications operated within 4.0-8.0 GHz. The proposed array microwave sensor comprises a Graphene array radiating patch, as well as ground and transmission lines with a substrate of Magnetite PDMS-Ferrite, which is fed by $50 \Omega$ coaxial ports. The Magnetite PDMS substrate associated with low permittivity and low loss tangent realized bandwidth enhancement and the high conductivity of graphene, contributing to a high gain of the UWB array antenna. The combination of $30 \%$ (ferrite) and $70 \%$ (PDMS) as the sensor's substrate resulted in low permittivity as well as a low loss tangent of 2.6 and 0.01 , respectively. The sensor radiated within the UWB band frequency of 2.2-11.2 (GHz) with great energy emitted in the range of 3.5-15.7 dB. Maximum energy of $15.7 \mathrm{~dB}$ with $90 \times 45(\mathrm{~mm})$ in small size realized the integration of the sensor for a microwave detection system. The material components of sensor could be implemented for solar panel.
\end{abstract}

Keywords: PDMS graphene array sensor; UWB spectrum; PDMS Ferrite

\section{Introduction}

Nowadays, the application of antennas as sensors is stressed most in terms of bandwidth and efficiency improvement despite miniaturization [1]. Substrate materials could play a vital role in influencing the characteristics stated above [2]. Normally, fer and Rogers as well as the FR-4 substrate are utilized to fabricate the antenna sensors for the conventional method. Reducing the wavelength of the relative permittivity dielectric guide could improve sensor bandwidth and efficiency, as well as the miniaturization of the sensor dimension [3,4]. However, these types of techniques result in thin bandwidth [5], low efficiency, and isolation [6], as well as reduce impedance matching [7].

Recently, a sensor made of a polymer composite substrate with preferable mechanical and electrical characteristics has attracted the interest of researchers. Various kinds of elements are composed with a variety of additions, possibly nickel ferrite, ceramic, and titanium [8]. One of the significant gains of applying dielectric with magnetic based relative permeability as well as permittivity to exceed the unity ( $\varepsilon r$ and $\mu r>1$ ) [9] is the miniaturization of the size of the probe [10]. Furthermore, such substrates also able to enhance the operated bandwidth of the sensor mentioned in [11,12].

Physically, sensors for microwave imaging must be compact, light, and planar [13]. Another study emphasizes that a sensor to detect a tumor must have features of low profile, high resolution (higher bandwidth), less complexity, lightweight, good efficiency, and good 
radiation directivity [14]. Other techniques for improving operated bandwidth that require additional structures towards the sensor, such as metasurface, metamaterial, and planar inverted, are not suitable to be applied and integrated into the sensor due to bulky and uneven structures which lead to uneven permeability and permittivity [15,16]. Polymeric substrates, such as the magnetic element of ferrite, which is well-distributed in nanoscale, have contributed to the stability of permittivity and permeability. Hence, it is very essential to have bandwidth improvement without compromising the other ideal features of the sensor, such as light, compact, low complexity, and low profile, which can be achieved by improvising the polymerization of the sensor's substrate [15].

PDMS is one the kind associated with flexibility, less permittivity, resistance to water, as well as the ability of mixing other elements to enable a variety of fabricated substrates for the antenna [17-19]. Incorporating PDMS and the magnetic element of ferrite could realize sensor bandwidth enhancement, as explained by Hansem and Burke, with the thickness $(t)$ effect of a magneto-dielectric towards bandwidth enhancement [12], as demonstrated in Equation (1):

$$
B W \cong \frac{96 \cdot \sqrt{\frac{\mu_{r}}{\varepsilon_{r}} \frac{t}{\lambda_{0}}}}{\sqrt{2} \cdot\left[4+17 \cdot \sqrt{\mu_{r} \varepsilon_{r}}\right]}
$$

On the other hand, Graphene has gained much interest among researchers to replace copper as a radiating material of the patch antenna sensor. A comprehensive Graphene study revealed graphene to be totally advanced compared to copper, single and multi-wall carbon nanotubes $[20,21]$. The features include $3.3 \times 10^{-1} \mathrm{~nm}$ (nano size), $10^{8} \mathrm{~s} / \mathrm{m}$ (high conductivity), $7.7 \times 10^{-1} \mathrm{mg} / 1 \mathrm{~m}$ (light element), and $150 \times 10^{6} \mathrm{psi}$ (strong element) of the single layer carbon atoms in 2-D honeycomb lattice constructed the Graphene.

As for detection purposes, using a microwave frequency range called microwave imaging, bandwidth and gain of the sensor are among the most important elements to be considered compared with others element [22]. The antenna performance relates to bandwidth, gain, radiation pattern directionality, and antenna efficiency, and these are essential to collect scattered signals to form a high-resolution image. Apart from that, the vital properties of graphene, namely high conductivity which leads to high gain, will serve as a promising alternative sensor material for cancer detection purposes due to the higher microwave signal required for human head structure penetration, including skin and skull, in order for the signal to reach the brain [23].

In this paper, a Graphene sensor array, which is fully embedded in a composite substrate of magnetic-based PDMS dielectric (PDMS-Ferrite), is presented as well as the study of the combination efficiency of the substrate and the graphene. This is done by comparing the proposed antenna sensor with a similarly dimensioned antenna fabricated on a dielectric (Taconic) substrate. Although the concept of PDMS-magneto materials has been reported in literature recently, the validation study towards the scientific relation between polymer dielectric with magnetic-based substrates and a Graphene sensor in terms of the bandwidth and gain described in this paper is among the earliest.

An overview of such antennas published in the literature is presented in Table 1 to determine that the antenna proposed in this work results in a significant bandwidth enhancement and gain in comparison to the state-of-the art. The low permittivity and low loss tangent of PDMS-Ferrite as well as the high conductivity of graphene have significantly contributed to the wide bandwidth and high gain of the Magnetite PDMS Graphene array sensor. Such gain, bandwidth, and small dimensions of $90 \times 45 \mathrm{~mm}^{2}$ make the UWB sensor suitable for microwave detection purposes [24]. 
Table 1. Different Antennas with Magneto-Dielectric Substrates.

\begin{tabular}{cccc}
\hline Ref & $\begin{array}{c}\text { Center Frequency } \\
\text { (GHz) }\end{array}$ & Bandwidth (GHz) & Max Gain (dB) \\
\hline$[25]$ & 2.1 & 0.039 & 2.4 \\
{$[26]$} & 0.85 & 0.1 & 5 \\
{$[27]$} & 0.8 & 0.077 & 5.1 \\
{$[28]$} & 2 & 0.2 & 1.5 \\
{$[29]$} & 2.0 & 6 & 5.3 \\
This work & 4.9 & 9 & 15.7 \\
(Magnetite PDMS & & & \\
Graphene Array sensor & & & \\
\hline
\end{tabular}

\section{Sensor Design and Fabrication Method}

The magnetite PDMS Graphene array sensor is generally constructed of Graphene to form an array circular patch, incorporate a feeding line, parasitic element, and partial ground, as well as PDMS-Ferrite to form magnetite dielectric substrate. For simulation, Graphene has been set to $3.8 \times 10^{8} \mathrm{~s} / \mathrm{m}$ for the conductivity value and PDMS-Ferrite is set to 2.6 and 0.01 for permittivity and loss tangent respectively. The array circular patch has been measured through specific calculation prior to being simulated using computer simulation software. Once being improved, the optimized patch size was determined at $15 \mathrm{~mm}$ in diameter. A $50 \Omega$ microstrip line acts as feed source placed at the center right back of the patch for direct connection between the feed source and patch. In order to realize high gain sensor, a single circular patch is multiplied to produce a $4 \times 1$ array. A corporate feeding structure is applied by adding feedlines for the connectivity of each patch. Identical power delivery of all patches could be realized by applying a quarter-wave transformer impedance matching method. Hence, $100 \Omega$ and $50 \Omega$ feedlines are coordinated using quarter wave transformers of $70.71 \Omega$ [30].

Figure 1 demonstrates the front, back, and top dimension of the proposed simulated sensor, constructed by graphene patches with the thickness of $0.03 \mathrm{~nm}$ and PDMS-Ferrite for the novel substrate element with thickness of $1.6 \mathrm{~mm}$. The introduction of a parasitic element as the new technique to realize ultra-wide band has the width of $8 \mathrm{~mm}$ and length of $32 \mathrm{~mm}$ with 0.02 gap with the transmission line. The parasitic element is the conductor material located near to radiating elements, yet it is not electrically connected with them. It functioned to provide electromagnetic coupling with the radiating elements by acting as a passive resonator. The waves from the parasitic elements do interfere by strengthening the antenna's radiation in the desired direction and cancelling out the waves in undesired directions [31]. The details of the geographical sizes of the sensor are demonstrated in Table 2.

Table 2. Geometrical Dimensions.

\begin{tabular}{cc}
\hline Parameter & Value $(\mathbf{m m})$ \\
\hline$W$ & 90 \\
$L$ & 45 \\
$R p$ & 15 \\
$P E_{g}$ & 0.2 \\
$P E_{l}$ & 8 \\
$P E_{w}$ & 30 \\
$P G_{l}$ & 15 \\
$P G_{w}$ & 32 \\
$R_{g}$ & 20 \\
\hline
\end{tabular}




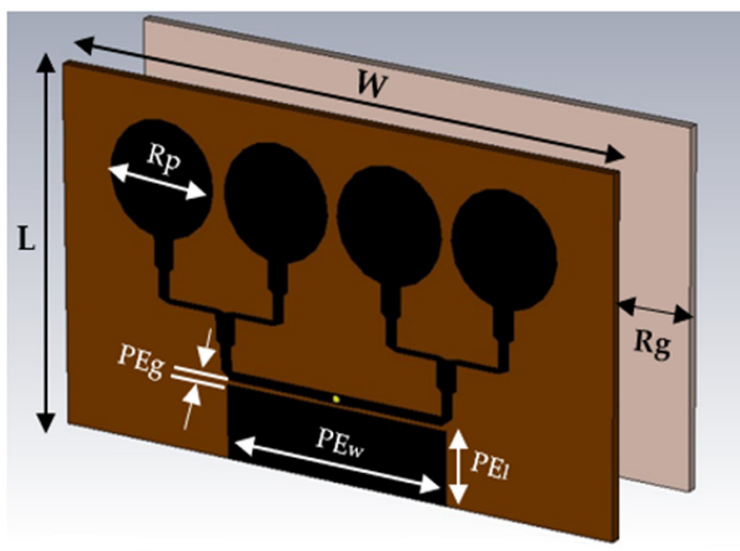

(a)

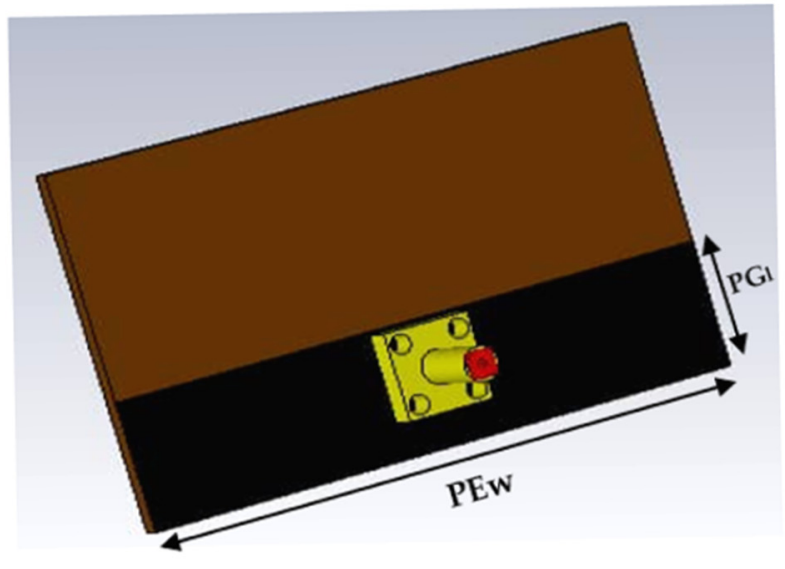

(b)

Figure 1. Simulated graphical propose sensor, (a) front and (b) back (transparent without reflector).

Figure 2 explains in detail the processing steps (flowchart) for synthesizing the Magnetite PDMS Graphene array sensor. The PDMS used has the permittivity of 2.8 while the graphene used has the carbon content, thickness, and conductivity of $97 \%, 25 \mu \mathrm{m}$, and $3.5 \times 10^{8} \mathrm{~s} / \mathrm{m}$, respectively [32]. On the other hand, Figure 3 demonstrates the synthesized Magnetite PDMS Graphene array sensor.

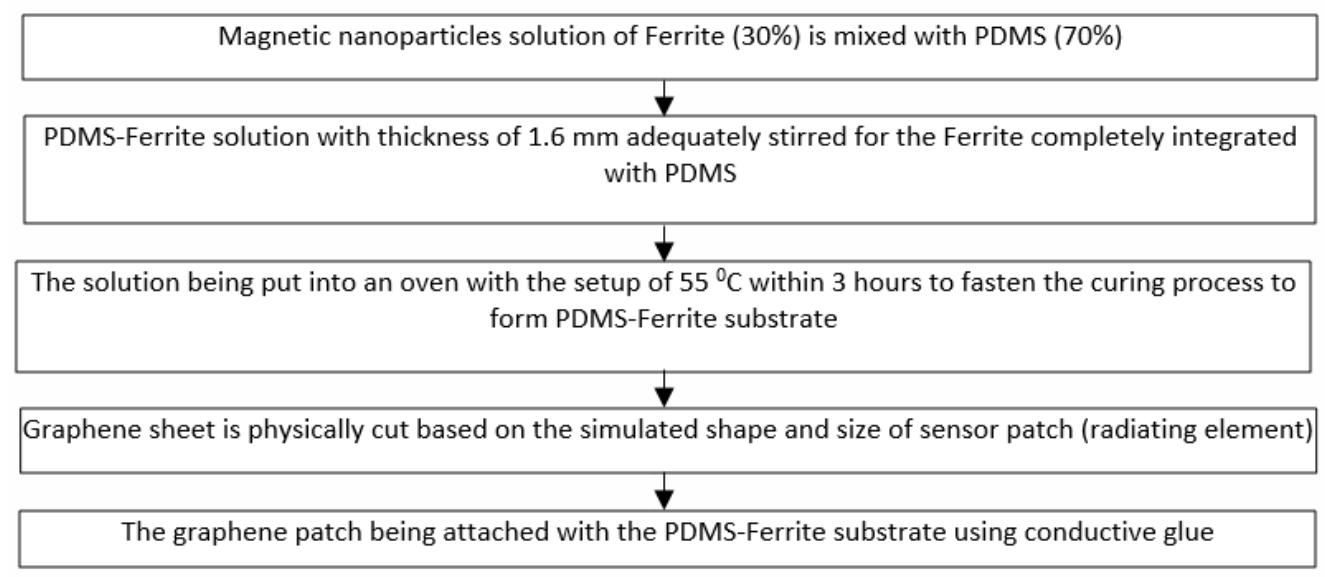

Figure 2. Processing steps for synthesizing the Magnetite PDMS Graphene Array Sensor.

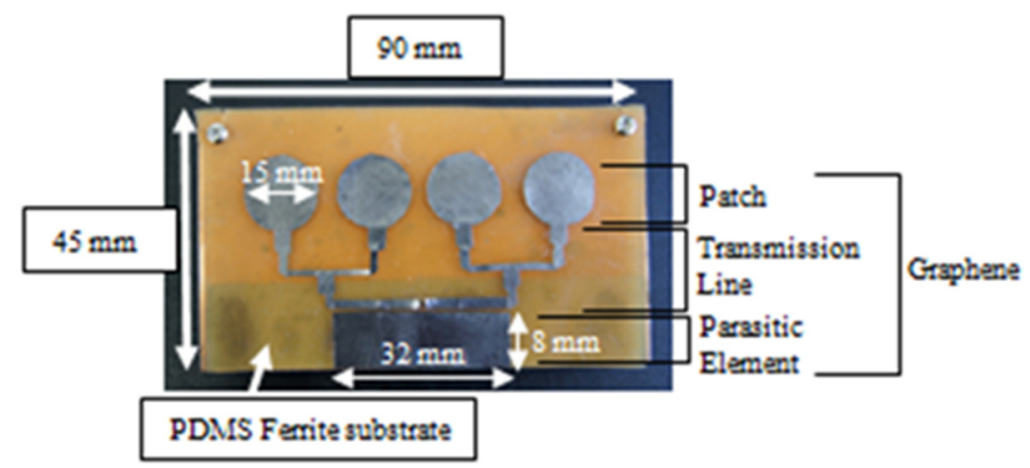

Figure 3. The synthesized Magnetite PDMS Graphene Array Sensor.

\section{Result and Discussion}

Magnetic Ferrite in three different ratios (25\%, 30\%, and 35\%) and PDMS (75\%, 70\%, and $65 \%$ ) is well blended respectively to realize three different mixed solutions of novel 
PDMS-Ferrite dielectric substrate with magnetic characteristics and a diversity of unique features. It is proven that the ratio of $30 \%$ iron oxide nanoparticles leads to improving dielectric properties which directly enhance the sensor performance. However, the sensor performance started to degrade once the ratio achieved $50 \%$ of Ferrite because of the excessive magnetic element existence leads to high magnetic losses. Figure 4 exhibits permittivity and loss tangent values according to different mixture composition of PDMSFerrite. Figure 4 demonstrates that $30 \%$ of ferrite concentration ratios recorded the lowest permittivity (2.6) and nearest value of zero (0.01) loss tangent constantly across the operated frequency as compared with concentration of $25 \%$ and $35 \%$. Hence, $30 \%$ and $70 \%$ of ferrite and PDMS concentration, respectively, is the ideal ratio to form the novel substrates for having a larger, more useful bandwidth. The negative loss tangent of the PDMS (75\%) and Ferrite (25\%) mixture, as shown in Figure $4 \mathrm{~b}$, is mainly obtained by the metallicity of the nanocomposites and the plasma oscillation of delocalized electrons. Theoretically, the negative permittivity can be explained by the Drude model. Due to the mass of atomic nucleus being much more than the electrons, the dipole phenomenon is attributed to the movement of a large number of electrons [33].

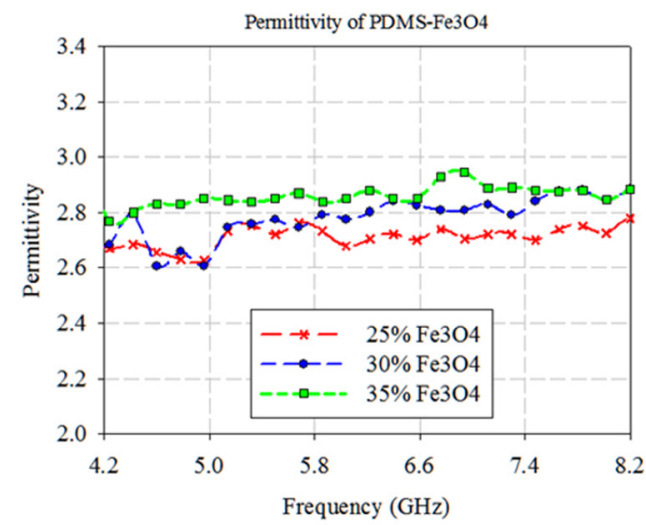

(a)

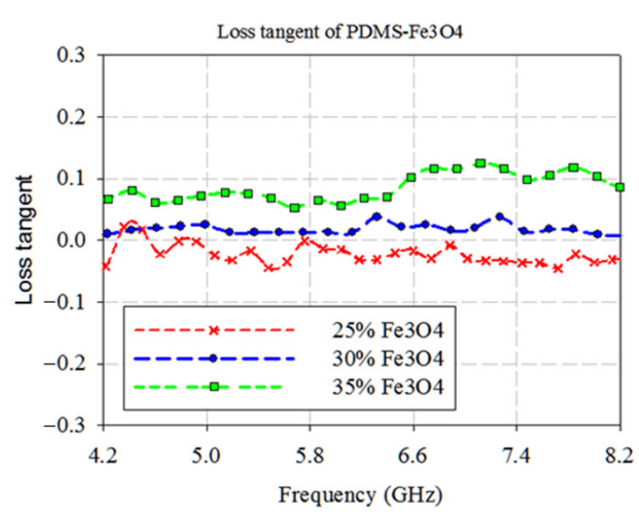

(b)

Figure 4. PDMS-Ferrite measurement results for permittivity (a) and loss tangent (b).

The PDMS-Ferrite substrate has been measured in terms of permittivity as well as loss tangent using a dielectric probe and VNA. The PDMS-Ferrite substrate measurement results for permittivity as well as loss tangent with $30 \%$ of Ferrite concentration in the form of liquid and solid are shown in Figure 5. Averages of 2.7 and 0.01 are the values recorded for permittivity and loss tangent measurement results respectively for the liquid PDMS-Ferrite substrate. Nevertheless, these values slightly increased to averages of 2.8 and 0.047 once PDMS-Ferrite substrate turned into solid form. On the other hand, the PDMSFerrite substrate recorded 1.4 for permeability determined using the Nicolson-Ross-Weir approach, as explained by [33]. Due to the different element construct FR4 and the proposed substrate, which are fiberglass and PDMS-Ferrite respectively, the sensor with FR4 substrate would exhibit a small bandwidth as compared to a sensor with PDMS-Ferrite as substrate which demonstrates large bandwidth because of the correlated effects of permeability, permittivity, and loss tangent [33]. 


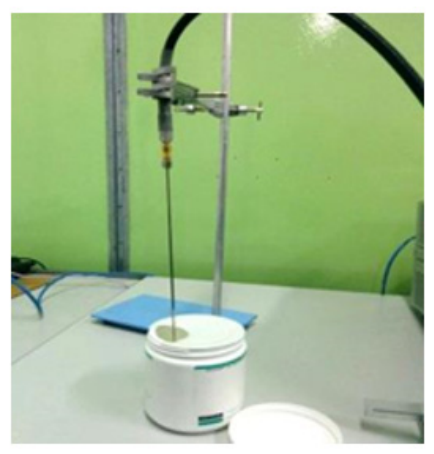

(a)

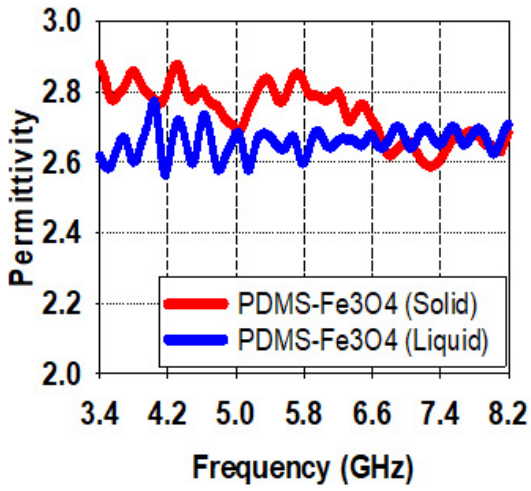

(c)

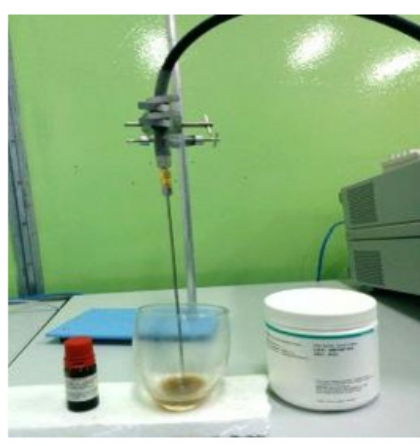

(b)

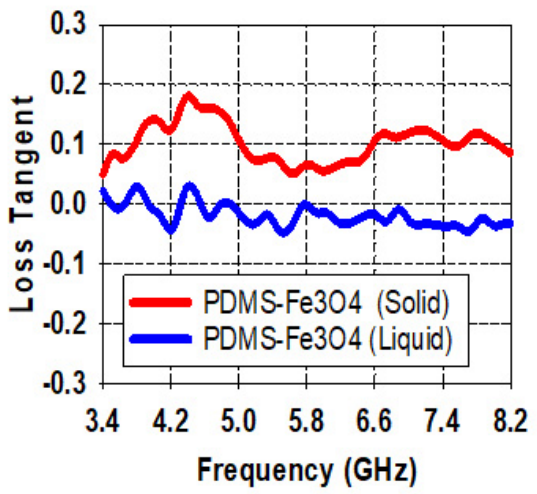

(d)

Figure 5. PDMS-Ferrite measurement results for dielectric characteristic; (a) liquid state and (b) solid state, result of measured permittivity PDMS in liquid and solid cases (c), and result of measured loss tangent PDMS in liquid and solid cases (d).

On the other hand, the waveguide approach is another method to determine PDMSFerrite permeability. Figure 6a illustrates how the approach applies the strong electric field at the waveguide center while Figure $6 \mathrm{~b}$ shows the strong magnetic field at the waveguide wall. Hence, material permittivity and permeability will be dominant as the material located at the middle and at the side wall respectively during transmission coefficient (S21). Figure $6 \mathrm{c}$ shows the measurement setup, which consists of an adapter for the coaxial waveguide, network analyzer, and G-band waveguide (support frequency: $3.95-5.85 \mathrm{GHz}$ ), while Figure $6 \mathrm{~d}$ indicates the location of sample for testing within the waveguide. Nevertheless, we failed to obtain a permeability calculation due to the extremely small reading of the sidewall, which resulted in an error through the transmission coefficient (S21). Thus, PDMS-Ferrite substrate electrical properties did not significantly alter with the presence of 30\% magnetic Ferrite. Due to that, the determination of the permittivity value obtained by taking into account the permeability of the sample is the air permeability obtained through the fitting method [34]. 


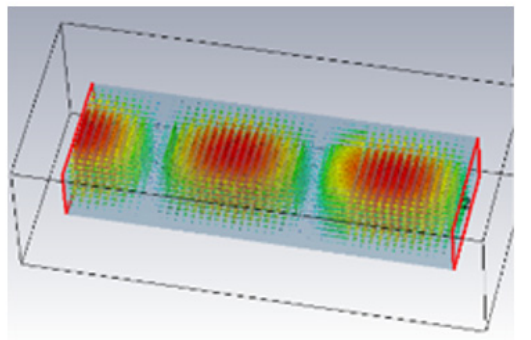

(a)

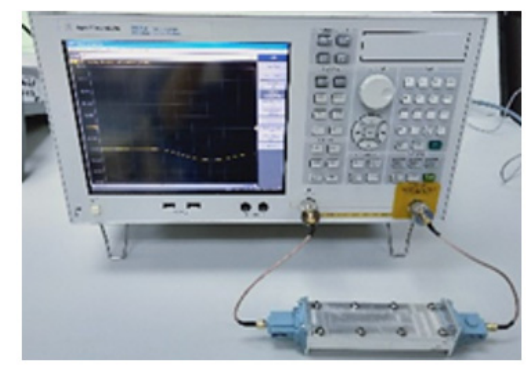

(c)

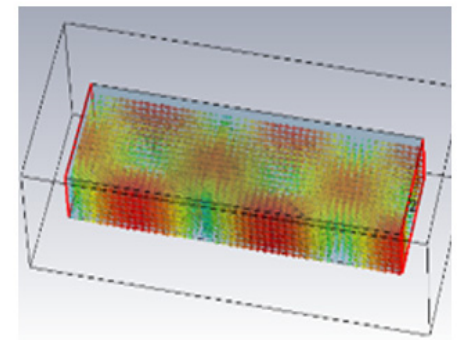

(b)

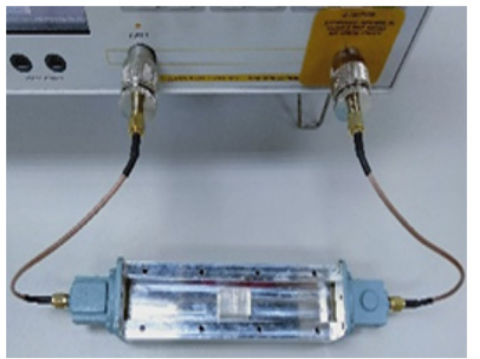

(d)

Figure 6. Waveguide technique for solid PDMS-Ferrite dielectric characteristic measurement; (a) strong electric filed at the waveguide center, (b) strong magnetic field at the waveguide wall, (c) measurement setup using waveguide technique, and (d) sample location for testing within the waveguide.

A study has been performed to investigate the optimum thickness of PDMS-Ferrite by varying the thickness of simulated PDMS-Ferrite in the range of $0.4-2.0 \mathrm{~mm}$, as shown in Figure 7. Based on the reflection coefficient (S11) simulated results shown in Figure 8, the optimum thickness of PDMS-Ferrite substrate is $1.6 \mathrm{~mm}$, as proposed in this paper due to the widest operated frequency $(9 \mathrm{GHz}$ ) recorded, from $2.2 \mathrm{GHz}$ to $11.2 \mathrm{GHz}$, as compared with the other operated frequency thicknesses.

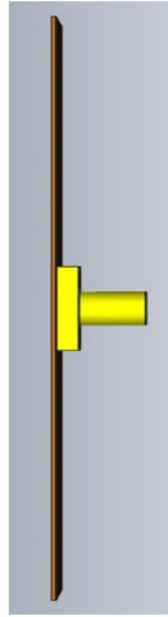

(a)

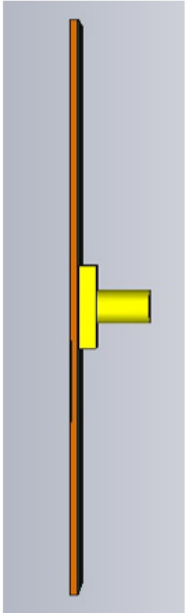

(b)

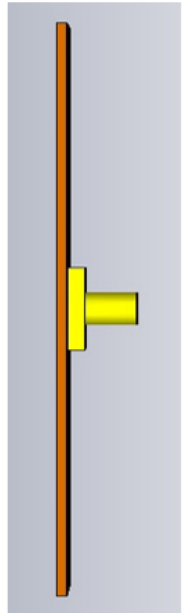

(c)

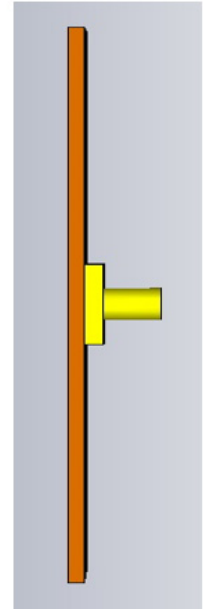

(d)

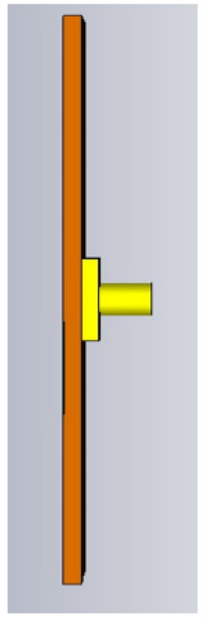

(e)

Figure 7. PDMS-Ferrite substrate thickness; (a) $0.4 \mathrm{~mm}$, (b) $0.8 \mathrm{~mm}$, (c) $1.2 \mathrm{~mm}$, (d) $1.6 \mathrm{~mm}$ and (e) $2.0 \mathrm{~mm}$. 


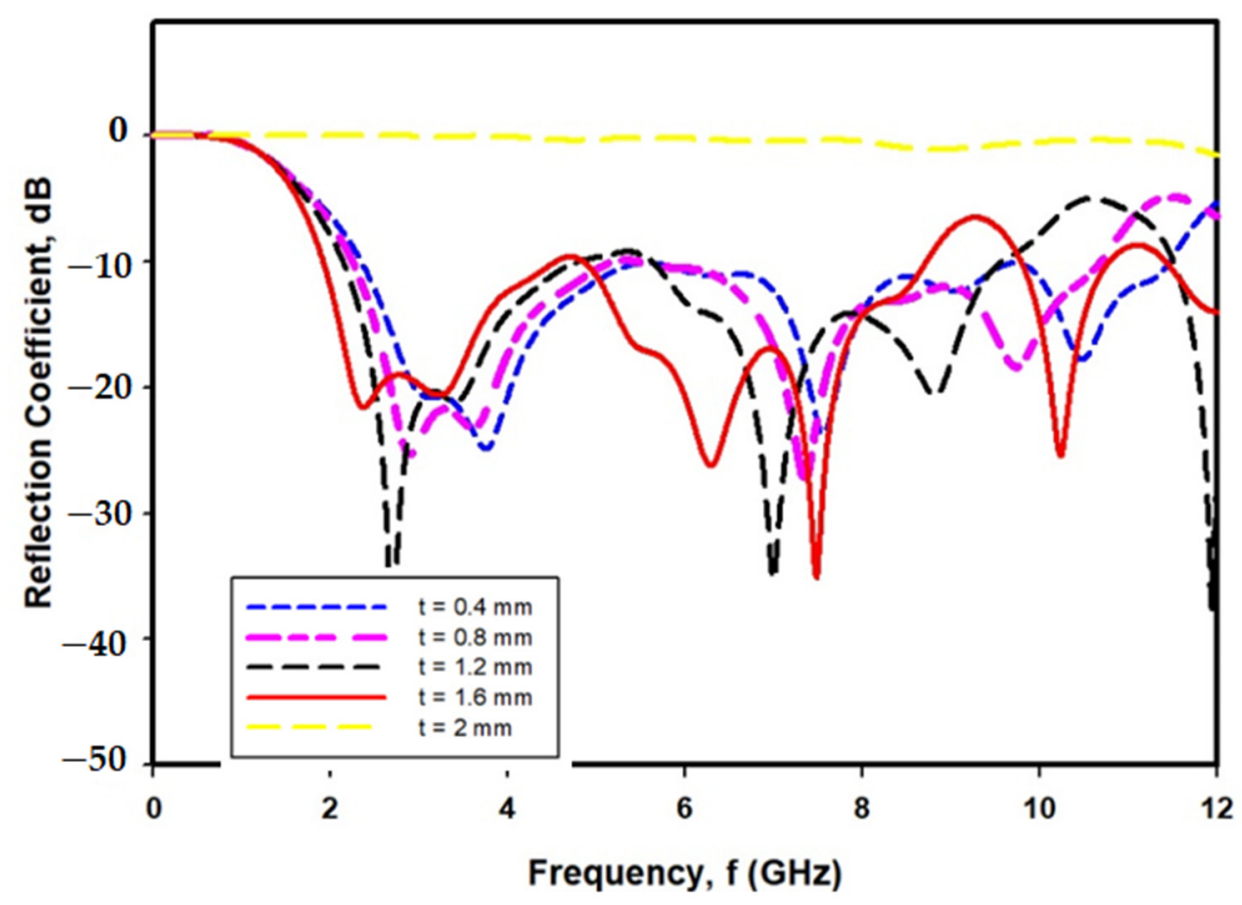

Figure 8. Operated bandwidth for Magnetite-PDMS Graphene Array sensor with different thickness of substrate.

The FESEM image of graphene in Figure 9a illustrates the formation of scattered groups of graphene sheets with a clear sign stacking. The graphene sheets look like a layer sheet morphology more than the outsized area owing to the large surface to volume ratio. A similar morphological nature of the graphene as closely stacked due to the elimination of an oxygen group to form a closely associated stack arrangement [35]. Meanwhile, XRD patterns of graphene are presented in Figure 9b, where the most intensive characteristic peak observed at $26.60^{\circ}$ corresponds to the (002) plane. This is clearly indicating the formation of pure graphite. As presented in Figure 9, the stacking sheets are closely linked to each other due to the interplanar distance and d-spacing reduction. The existence of graphene single layer structures and vanishing multilayer component will increase the greater spreading peak. The decreasing of the size of sheets with a shapeless arrangement is formed from a broad hump at $2 \theta=20-30^{\circ}$ [36].

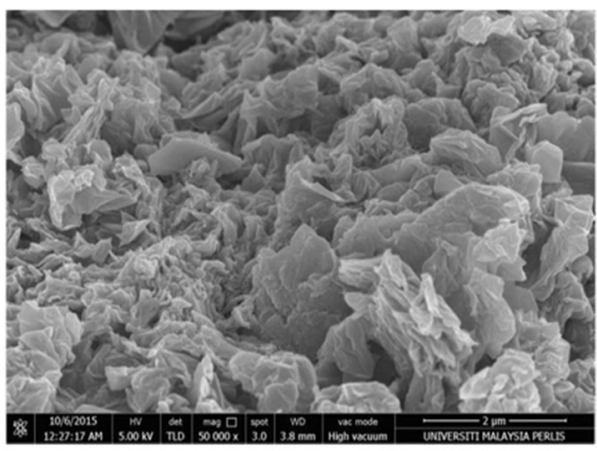

(a)

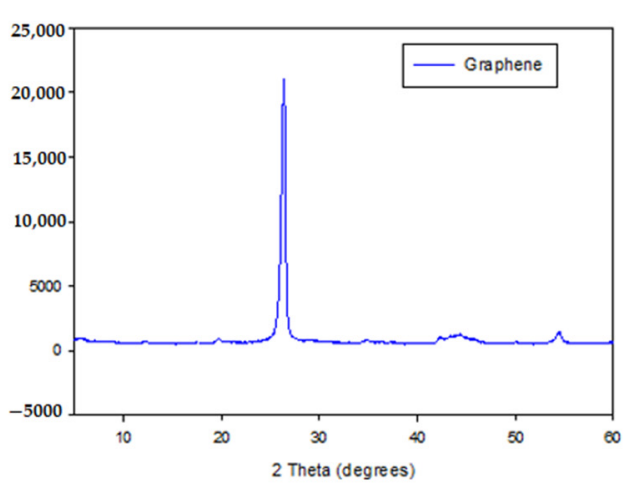

(b)

Figure 9. Characterization of Graphene (a) FESEM images (50,000 times of magnifying), (b) XRD pattern.

A four point probe device was used to measure graphene conductivity, as shown in Figure 10. From the measurements, graphene is found to feature a conductivity of $3.38 \times 10^{8} \mathrm{~s} / \mathrm{m}$, resistivity of $2.01 \times 10^{-3} \Omega$. m, voltage of $0.2 \mathrm{~V}$, and current of $9.48 \times 10^{-1} \mathrm{~A}$. 
The measured high conductivity and low resistivity values are good in agreement with early reported work on the conductivity and resistivity of graphene by several researchers [37]. The observed electrical properties are enough to be utilized as a conductive material to replace copper and other metals for various applications. The chemical with microwave assisted combination process-based reduction method is playing a prime role to enhance the electrical properties [38].

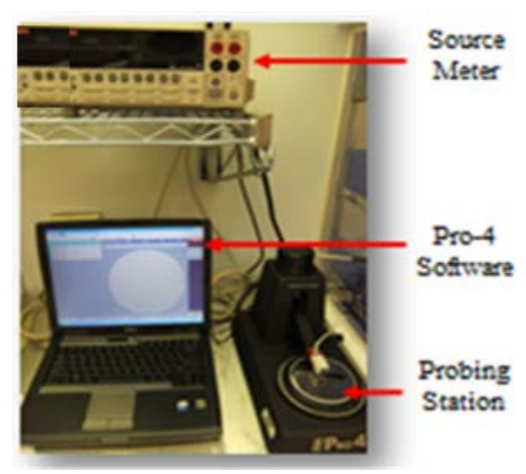

Figure 10. Four point probe device.

Fabricated sensors of the Magnetite PDMS Graphene array and Copper-Taconic are illustrated in Figure 11a,b correspondingly while Figure 12a,b presents the measured comparisons of S-parameters and gain of the two sensors. The proposed Magnetite PDMS Graphene array sensor operated within the frequency range of $2.2-11.2(\mathrm{GHz})$ while Copper-Taconic resonates within the range of 4.2-11.2 (GHz). The gain of Magnetite PDMS Graphene array sensor is significantly higher $(15.7 \mathrm{~dB})$ than Copper-Taconic, which is 13.5 $\mathrm{dB}$. The bandwidth and maximum gain of the Magnetite PDMS Graphene array sensor has been increased up to $28 \%(2 \mathrm{GHz})$ and $2.2 \mathrm{~dB}$ respectively. The ideal dielectric properties of low permittivity and low loss tangent of Magnetite PDMS-Ferrite as well as the high conductivity of graphene significantly contributed to the wide bandwidth and high gain of the Magnetite PDMS Graphene array sensor.

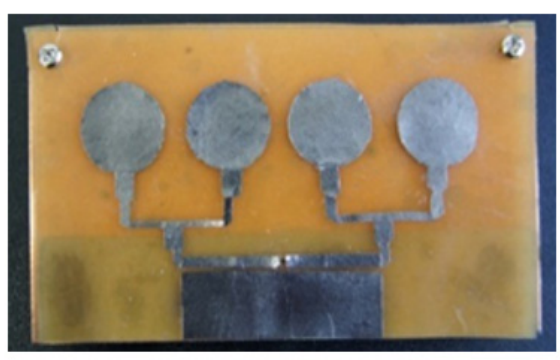

(a)

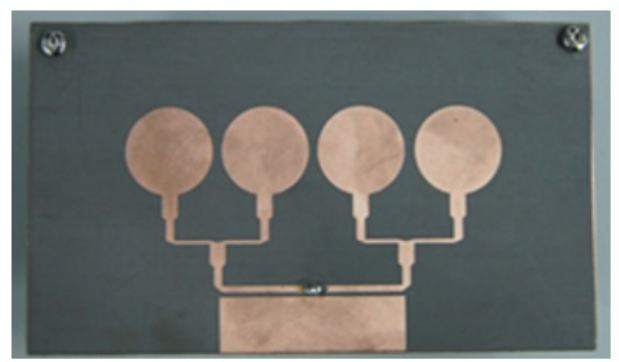

(b)

Figure 11. Comparison of fabricated antenna sensors (a) Magnetite PDMS Graphene Arraysensor and (b) Copper-Taconic sensor.

On the other hand, the Magnetite PDMS Graphene array sensor E-plane radiation pattern at frequency of $3,4,5$, and $6 \mathrm{GHz}$ is shown in Figure 13. Those frequencies achieved among the highest gain and the longest wavelengths recorded by the sensor. A uni-directional radiation pattern recorded ensured that the sensor was able to emit the signals throughout ultra-wideband frequency [39]. The patterns exhibit the average directivity of $7.4 \mathrm{~dB}$ while the highest was recorded at $15.7 \mathrm{~dB}$. 


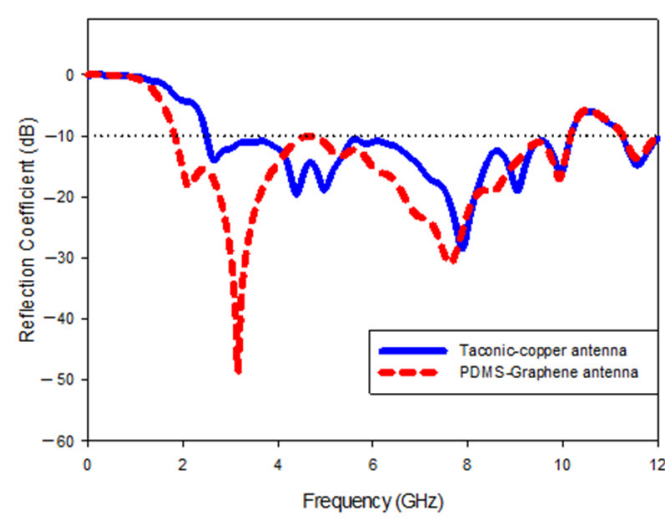

(a)

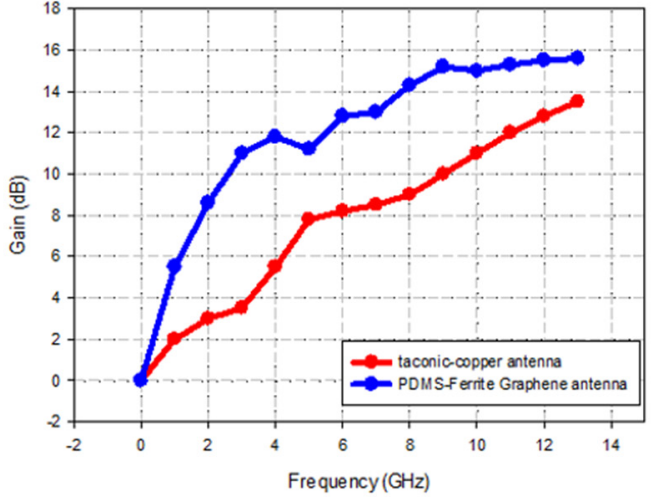

(b)

Figure 12. Magnetite PDMS Graphene Array and Copper-Taconic Sensor; (a) operated bandwidth, (b) gain.

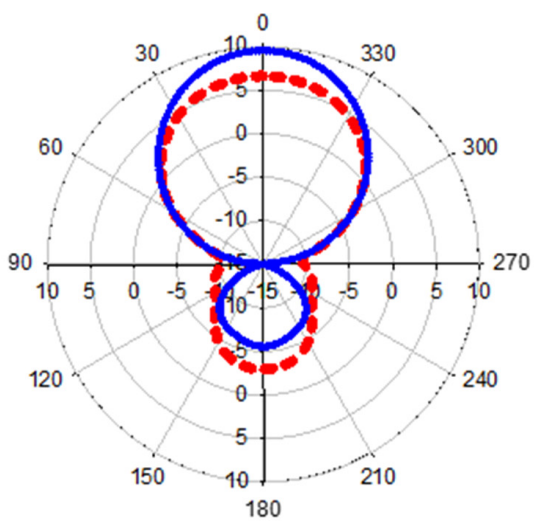

(a)

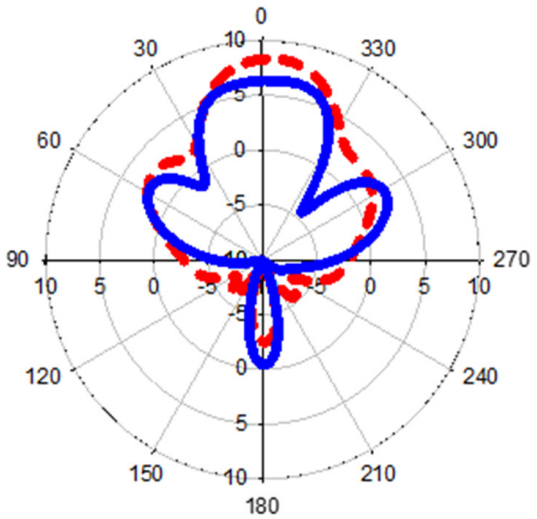

(c)

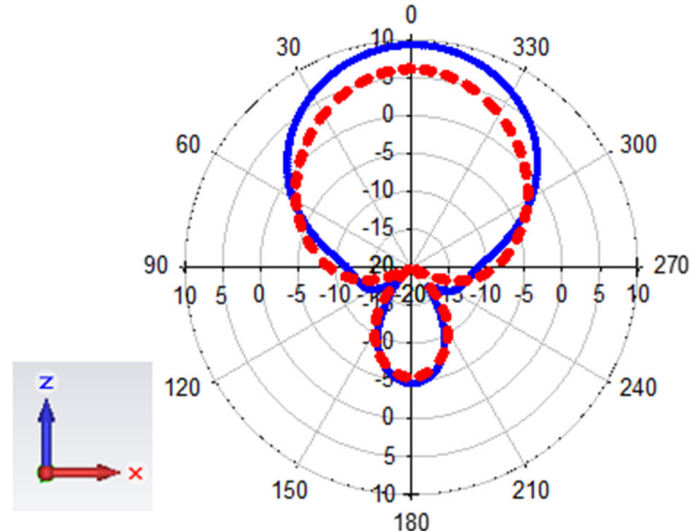

(b)

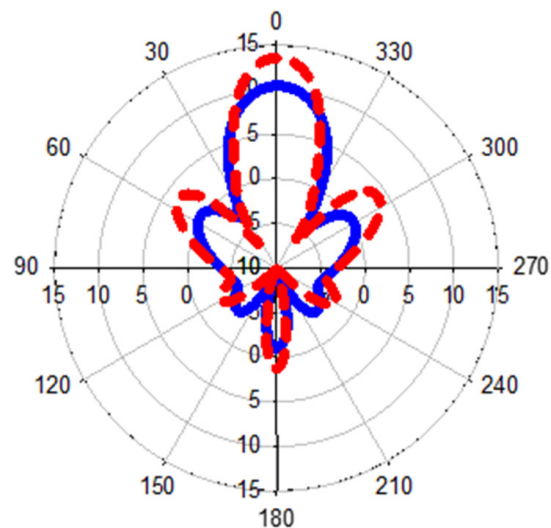

(d)

Figure 13. E-plane radiation pattern in red colour (simulated) and blue colour (measured) for (a) $3 \mathrm{GHz}$, (b) $4 \mathrm{GHz}$, (c) $5 \mathrm{GHz}$, (d) $6 \mathrm{GHz}$.

\section{Conclusions}

In a nutshell, the addition of a magnetic element, Ferrite, to a PDMS solution enables to reduce the permittivity value and loss tangent of the sensor substrate. Ferrite and PDMS with in the proportion of $30 \%$ and $70 \%$ each were selected and integrated to realize low permittivity as well as low loss tangent of 2.6 and 0.01 correspondingly for the Magnetite 
PDMS Graphene array sensor substrate. The proposed sensor recorded UWB operated frequency within the range of 2.2-11.2 (GHz) and great energy was emitted in the range of 3.5-15.7 $\mathrm{dB}$ due to ferrite relative permeability as well as permittivity exceeding the unity ( $\varepsilon r$ and $\mu \mathrm{r}>1$ ) and low permittivity of PDMS. The sensor with PDMS-Ferrite substrate managed to have bandwidth enlargement as much as $28 \%$, which is equal to $2 \mathrm{GHz}$ for this paper as compared with the conventional Taconic substrate. In terms of the gain, the proposed Magnetite PDMS Graphene Array sensor recorded the maximum gain of $15.7 \mathrm{~dB}$ compared with Copper-Taconic antenna which recorded $13.5 \mathrm{~dB}$ for maximum gain due to the presence of graphene as the radiating element that has a conductivity value $\left(3.7 \times 10^{8}\right)$ higher than copper $\left(3.7 \times 10^{7}\right)$.

Author Contributions: Conceptualization, M.A.J.; Data curation, M.F.J. and M.S.A.K.; Formal analysis, A.A.; Investigation, W.A.M.; Methodology, W.A.M.; Software, M.A.J.; Supervision, P.A.; Writingreview \& editing, P.A. All authors have read and agreed to the published version of the manuscript.

Funding: The authors would like to thank the Ministry of Higher Education for providing largest financial support under Fundamental Research Grant Scheme (FRGS) No. FRGS/1/2019/STG02/UMP/ 02/4 (University reference RDU1901184), Universiti Malaysia Pahang for additional financial support under Internal Research grant RDU190349 and King Mongkut's University of Technology North Bangkok grant number [KMUTNB-FF-65-21].

Institutional Review Board Statement: Not applicable.

Informed Consent Statement: Not applicable.

Data Availability Statement: Not applicable.

Acknowledgments: The authors would like to thank the Ministry of Higher Education for providing largest financial support, Universiti Malaysia Pahang for additional financial support and King Mongkut's University of Technology North Bangkok grant.

Conflicts of Interest: The authors declare no conflict of interest.

\section{References}

1. Mosallaei, H.; Sarabandi, K. Antenna miniaturization and bandwidth enhancement using a reactive impedance substrate. IEEE Trans. Antennas Propag. 2004, 52, 2403-2414. [CrossRef]

2. Sze, J.Y.; Wong, K.L. Bandwidth enhancement of a microstrip-line-fed printed wide-slot antenna. IEEE Trans. Antennas Propag. 2001, 49, 1020-1024. [CrossRef]

3. Karilainen, A.O.; Ikonen, P.M.; Simovski, C.R.; Tretyakov, S.A. Choosing dielectric or magnetic material to optimize the bandwidth of miniaturized resonant antennas. IEEE Trans. Antennas Propag. 2011, 59, 3991-3998. [CrossRef]

4. Hwang, Y.; Zhang, Y.P.; Zheng, G.X.; Lo, T.K.C. Planar inverted F antenna loaded with high permittivity material. Electron. Lett. 1995, 31, 1710-1712. [CrossRef]

5. Huynh, A.; Long, S.; Jackson, D. Effects of permittivity on bandwidth and radiation patterns of cylindrical dielectric resonator antennas. In Proceedings of the 2010 IEEE Antennas and Propagation Society International Symposium, Toronto, ON, Canada, 11-17 July 2010; pp. 1-4.

6. Isa, M.M.; Langley, R.; Khamas, S.; Isa, A.A.M.; Zin, M.; Johar, F.; Zakaria, Z. Microstrip Patch Antenna Array Mutual Coupling Reduction using Capacitive Loaded Miniaturized EBG. J. Telecommun. Electron. Comput. Eng. 2012, 4, 27-34.

7. Namin, F.; Spence, T.; Werner, D.; Semouchkina, E. Broadband, Miniaturized Stacked-Patch Antennas for L-Band Operation Based on Magneto-Dielectric Substrates. IEEE Trans. Antennas Propag. 2010, 58, 2817-2822. [CrossRef]

8. Choi, D.; Choi, M.; Kim, J. Magnetic Properties of Fe@ FeSiAl Oxide Nanoparticles and Magneto-Dielectric Properties of Their Composite Sheets. IEEE Trans. Antennas Propag. 2014, 50,1-4. [CrossRef]

9. Attia, H.; Yousefi, L.; Bait-Suwailam, M.M.; Boybay, M.S.; Ramahi, O.M. Enhanced-gain microstrip antenna using engineered magnetic superstrates. IEEE Antennas Wirel. Propag. Lett. 2009, 8, 1198-1201. [CrossRef]

10. Buell, K.; Mosallaei, H.; Sarabandi, K. A substrate for small patch antennas providing tunable miniaturization factors. IEEE Trans. Microw. Theory Tech. 2006, 54, 135-146. [CrossRef]

11. Niamien, C.; Collardey, S.; Sharaiha, A.; Mahdjoubi, K. Compact expressions for efficiency and bandwidth of patch antennas over lossy magneto-dielectric materials. IEEE Antennas Wirel. Propag. Lett. 2011, 10, 63-66. [CrossRef]

12. Hansen, R.C.; Burke, M. Antennas with magneto-dielectrics. Microw. Opt. Technol. Lett. 2000, 26, 75-78. [CrossRef]

13. Adnan, S.; Abd-Alhameed, R.A.; Hraga, H.I.; Elfergani, I.T.; Child, M.B. Compact Microstrip Antenna Design for Microwave Imaging. In Proceedings of the 2010 Loughborough Antennas \& Propagation Conference, Loughborough, UK, 8-9 November 2010. 
14. Hossain, A.; Islam, M.T.; Islam, M.T.; Chowdhury, M.E.H.; Rmili, H.; Samsuzzaman, M. A Planar Ultrawideband Patch Antenna Array for Microwave Breast Tumor Detection. Materials 2020, 13, 4918. [CrossRef]

15. Raveendran, A.; Sebastian, M.T.; Raman, S. Applications of Microwave Materials: A Review. J. Electron. Mater. 2019, 48, 2601-2634. [CrossRef]

16. Hossain, T.M.; Jamlos, M.F.; Jamlos, M.A.; Soh, P.J.; Islam, M.I.; Khan, R. Modified H-shaped DNG metamaterial for multiband microwave application. Appl. Phys. A 2018, 124, 183. [CrossRef]

17. Kilian, A.; Schmidt, L. A novel fabrication process for printed antennas integrated in polymer multi-layer car body panels. In Proceedings of the 2009 European Microwave Conference (EuMC), Rome, Italy, 29 September-1 October 2009; pp. 578-581.

18. Hage-Ali, S.; Tiercelin, N.; Coquet, P.; Sauleau, R.; Fujita, H.; Preobrazhensky, V.; Pernod, P. A millimeter-wave microstrip antenna array on ultra-flexible micromachined polydimethylsiloxane (PDMS) polymer. IEEE Antennas Wirel. Propag. Lett. 2009, 8 , 1306-1309. [CrossRef]

19. Alqadami, A.S.M.; Jamlos, M.F.; Soh, P.J.; Vandenbosch, G.A.E. Assessment of PDMS technology in a MIMO antenna array. IEEE Antennas Wirel. Propag. Lett. 2015, 15, 1939-1942. [CrossRef]

20. Chaudhary, S.; Luthra, P.K.; Kumar, A. Use of Graphene as a Patch Material in comparison to the copper and other Carbon Nanomaterials. Int. J. Emerg. Technol. Comput. Appl. Sci. 2013, 3, 272-279.

21. Barkauskas, J.; Mikoliunaite, L.; Paklonskaite, I.; Genys, P.; Petroniene, J.J.; Morkvenaite-Vilkonciene, I.; Ramanaviciene, A.; Samukaite-Bubniene, U.; Ramanavicius, A. Single-walled carbon nanotube based coating modified with reduced graphene oxide for the design of amperometric biosensors. Mater. Sci. Eng. C 2019, 98, 515-523. [CrossRef]

22. Islam, M.T.; Samsuzzaman, M.; Kibria, S.; Misran, N. Metasurface Loaded High Gain Antenna based Microwave Imaging using Iteratively Corrected Delay Multiply and Sum Algorithm. Sci. Rep. 2019, 9, 17317. [CrossRef]

23. Jamlos, M.A.; Jamlos, M.F.; Ismail, A.H. High performance novel UWB array antenna for brain tumor detection via scattering parameters in microwave imaging simulation system. In Proceedings of the 20159 th European Conference on Antennas and Propagation (EuCAP), Lisbon, Portugal, 13-17 April 2015; pp. 1-5.

24. Mohammed, B.J.; Abbosh, A.M.; Mustafa, S.; Ireland, D. Microwave System for Head Imaging. IEEE Trans. Instrum. Meas. 2014, 63, 117-123. [CrossRef]

25. Yang, G.; Xing, X.; Obi, O.; Daigle, A.; Liu, M.; Stoute, S.; Naishadham, K.; Sun, N.X. Loading effects of self-biased magnetic films on patch antennas with substrate/superstrate sandwich structure. IET Microw. Antennas Propag. 2010, 4, 1172-1181. [CrossRef]

26. Huitema, L.; Reveyrand, T.; Mattei, J.; Arnaud, E.; Decroze, C.; Monediere, T. Frequency tunable antenna using a magnetodielectric material for DVB-H Application. IEEE Trans. Antennas Propag. 2013, 61, 4456-4466. [CrossRef]

27. Shin, Y.S.; Park, S.O. A monopole antenna with a magneto-dielectric material and its MIMO application for $700 \mathrm{MHz}-\mathrm{LTE}-\mathrm{band}$ Microw. Opt. Technol. Lett. 2010, 52, 2364-2367. [CrossRef]

28. Lee, J.; Heo, J.; Lee, J.; Han, Y. Design of small antennas for mobile handsets using magneto-dielectric material. IEEE Trans. Antennas Propag. 2012, 60, 2080-2084. [CrossRef]

29. Ermutlu, M.; Simovski, C.; Karkainen, M.; Ikonen, P.; Sochava, A.; Tretyakov, S. Patch antennas with new artificial magnetic layers. arXiv 2005, arXiv:physics/0504075.

30. Jamlos, M.A.; Jamlos, M.F.; Khatun, S.; Ismail, A.H. An optimum quarter-wave impedance matching feedline for circular UWB array antenna with high gain performance. In Proceedings of the 2014 IEEE Symposium on Wireless Technology and Applications (ISWTA), Kota Kinabalu, Malaysia, 28 September-1 October 2014; pp. 165-169.

31. Jamlos, M.A.; Jamlos, M.F.; Ismail, A.H. High performance of coaxial feed UWB antenna with parasitic element for microwave imaging. Microw. Opt. Technol. Lett. 2015, 57, 649-653. [CrossRef]

32. Graphene Supermarket, Graphene Coatings/Films, Conductive Graphene Sheet. Available online: https://graphenesupermarket.com/Conductive-Graphene-Sheets.html (accessed on 15 June 2015).

33. Qin, G.; Qiu, J. Graphene/polypyrrole nanocomposites with high negative permittivity and low dielectric loss tangent. Ceram. Int. 2019, 45, 5407-5412. [CrossRef]

34. Karim, M.S.B.A.; Konishi, Y.; Kitazawa, T. Robustness analysis of simultaneous determination method of complex permittivity and permeability. In Proceedings of the 2014 International Conference on Numerical Electromagnetic Modeling and Optimization for RF, Microwave, and Terahertz Applications (NEMO), Pavia, Italy, 14-16 May 2014; pp. 1-4.

35. Karim, M.S.; Konishi, Y.; Harafuji, K.; Kitazawa, T. Determination of Complex Permittivities of Layered Materials Using Waveguide Measurements. IEEE Trans. Microw. Theory Tech. 2014, 62, 2140-2148. [CrossRef]

36. Muthoosamy, K.; Bai, R.G.; Abubakar, I.B.; Sudheer, S.M.; Lim, H.N.; Loh, H.; Huang, N.M.; Chia, C.H.; Manickam, S. Exceedingly biocompatible and thin-layered reduced graphene oxide nanosheets using an eco-friendly mushroom extract strategy. Int. J. Nanomed. 2015, 10, 1505-1519.

37. Chen, W.; Yan, L.; Bangal, P.R. Preparation of graphene by the rapid and mild thermal reduction of graphene oxide induced by microwaves. Carbon 2010, 48, 1146-1152. [CrossRef]

38. Viana, M.M.; Lima, M.C.F.S.; Forsythe, J.C.; Gangoli, V.S.; Cho, M.; Cheng, Y.; Silva, G.G.; Wong, M.S.; Caliman, V. Facile Graphene Oxide Preparation by Microwave-Assisted Acid Method. J. Braz. Chem. Soc. 2015, 26, 978-984. [CrossRef]

39. Nayan, M.K.A.; Jamlos, M.F.; Lago, H.; Jamlos, M.A. Two-port circular polarized antenna array for point-to-point communication. Microw. Opt. Technol. Lett. 2015, 57, 2328-2332. [CrossRef] 